\title{
Intracluster correlation coefficients for the Brazilian Multicenter Study on Preterm Birth (EMIP): methodological and practical implications
}

Giuliane J Lajos ${ }^{1 *}$, Samira M Haddad ${ }^{1}$, Ricardo P Tedesco ${ }^{1}$, Renato Passini Jr ${ }^{1}$, Tabata Z Dias ${ }^{1}$, Marcelo L Nomura ${ }^{1}$, Patrícia M Rheder ${ }^{1}$, Maria H Sousa ${ }^{2}$, and Jose G Cecatti ${ }^{1,2}$ for the Brazilian Multicenter Study on Preterm Birth study group

\begin{abstract}
Background: Cluster-based studies in health research are increasing. An important characteristic of such studies is the presence of intracluster correlation, typically quantified by the intracluster correlation coefficient (ICC), that indicate the proportion of data variability that is explained by the way of clustering. The purpose of this manuscript was to evaluate ICC of variables studied in the Brazilian Multicenter Study on Preterm Birth.

Methods: This was a multicenter cross-sectional study on preterm births involving 20 referral hospitals in different regions of Brazil plus a nested case-control study to assess associated factors with spontaneous preterm births. Estimated prevalence rates or means, ICC with 95\% confidence intervals, design effects and mean cluster sizes were presented for more than 250 maternal and newborn variables.

Results: Overall, 5296 cases were included in the study (4,150 preterm births and 1,146 term births). ICC ranged from $<0.001$ to 0.965 , with a median of 0.028 . For descriptive characteristics (socio-demographic, obstetric history and perinatal outcomes) the median ICC was 0.014 , for newborn outcomes the median ICC was 0.041 and for process variables (clinical management and delivery), it was 0.102 . ICC was $<0.1$ in $78.4 \%$ of the variables and $<0.3$ for approximately $95 \%$ of them. Most of ICC $>0.3$ was found in some clinical management aspects well defined in literature such as use of corticosteroids, indicating there was homogeneity in clusters for these variables.
\end{abstract}

Conclusions: Clusters selected for Brazilian Multicenter Study on Preterm Birth had mainly heterogeneous findings and these results can help researchers estimate the required sample size for future studies on maternal and perinatal health.

Keywords: Intracluster correlation coefficient, Preterm birth, Spontaneous preterm labor, Premature rupture of membranes, Indicated preterm delivery, Neonatal morbidity

\section{Background}

Cluster-based studies involving aggregated units such as hospitals, health centers, schools or medical practices are increasingly being used in healthcare evaluation, especially in cluster randomized trials, which are perhaps the most high impact form of public health research/ evaluation study design that can benefit from good extent estimates of ICC. In such situations, population

\footnotetext{
*Correspondence: giuliane@unicamp.br

${ }^{1}$ Department of Obstetrics and Gynecology, School of Medical Sciences,

University of Campinas, Campinas, Brazil

Full list of author information is available at the end of the article
}

groups (specific geographical areas), healthcare units (hospitals) or healthcare sectors are considered primary sampling units and generally all subjects belonging to each group are included to obtain data of interest [1,2].

However, depending on the method of selection, data obtained from clusters may not be sufficiently representative to allow for generalization. Population observed in clusters can present a large degree of similarity in some characteristics (homogeneity), unlike when there is a simple random sampling (SRS), in which each individual has the same probability of being selected in the general population, with more heterogeneity [2]. 
Therefore, an important characteristic of cluster-based studies is to evaluate the proportion of data variability that is explained by means of clustering, and this reliability may be analyzed by measuring inter and intracluster variance [3].

Intracluster correlation coefficient (ICC), denoted by $\rho$, is defined as the ratio of the between-cluster variance to the total variance (both between and within clusters), and therefore has a value between 0 and 1 [4,5]. Its value depends on the type of variable, cluster size and the prevalence of the condition [6]. Coefficients close to zero indicate that individuals within clusters are no more similar to each other than individuals from different clusters (the variable is randomly distributed among clusters); otherwise the values close to 1 reflect the homogeneity in a sample [7]. In other words, for cluster based population studies this heterogeneity (ICC close to zero) is desired as a proxy to the subjects being randomly selected.
The increase in variance due to clustering, compared to what would be obtained if sampling had been carried out by the SRS method, is calculated by design effect (Deff) [8]. It is given by $1+(m-1)$ ICC, where $m$ is the average cluster size [9]. Deff value is directly proportional to ICC and to the size of a cluster [10].

The ICC estimate in cluster studies is very useful for the development of new studies in the same field, because values obtained could be used as a correction factor for the calculation of sample size needed, thus avoiding underestimates, since in studies in which SRS is used, the sample size required to achieve sufficient statistical power is usually smaller [4].

The purpose of this manuscript is to evaluate the ICC of variables studied in the Brazilian Multicenter Study on Preterm Birth, a multicenter cross-sectional study on preterm births involving 20 referral hospitals in different regions of Brazil plus a nested case-control study. Estimated prevalence rates or means, ICC with 95\%

Table 1 Estimates of prevalence (P), intracluster correlation coefficients (ICC), their respective $95 \% \mathrm{Cl}$, design effect (Deff), and mean cluster size $\left(n_{a}\right)$ for categorical maternal characteristics

\begin{tabular}{|c|c|c|c|c|c|}
\hline Variables & $\mathrm{P}(\%)$ & ICC & $95 \% \mathrm{Cl}$ for ICC & Deff & $\mathrm{n}_{\mathrm{a}}$ \\
\hline Skin color (white) & 43.1 & 0.145 & $0.058-0.233$ & 42.2 & 265 \\
\hline Marital status (with a partner) & 77.7 & 0.008 & $<0.001-0.016$ & 3.2 & 265 \\
\hline Schooling (>8 years) & 60.5 & 0.030 & $0.008-0.053$ & 10.6 & 261 \\
\hline Children under 5 years $(\geq 1)$ & 27.1 & 0.005 & $<0.001-0.011$ & 2.4 & 265 \\
\hline Time since last delivery (until 12 months) & 8.4 & 0.011 & $<0.001-0.022$ & 2.8 & 155 \\
\hline Previous cerclage & 1.1 & 0.001 & $<0.001-0.004$ & 1.2 & 264 \\
\hline Previous preterm birth & 17.3 & 0.007 & $<0.001-0.013$ & 3.2 & 264 \\
\hline Previous preterm birth of multiples & 1.0 & $<0.001$ & $<0.001-0.003$ & 1.2 & 264 \\
\hline Previous preterm labor & 7.4 & 0.011 & $0.001-0.021$ & 4.3 & 264 \\
\hline Previous prelabor PROM & 7.2 & 0.002 & $<0.001-0.006$ & 1.8 & 264 \\
\hline Previous indicated preterm birth & 7.7 & 0.004 & $<0.001-0.009$ & 2.0 & 263 \\
\hline Previous newborn weight $<2500 \mathrm{~g}$ & 14.8 & 0.010 & $<0.001-0.019$ & 4.1 & 262 \\
\hline \multicolumn{6}{|l|}{ Previous chronic diseases: } \\
\hline - Chronic hypertension & 8.2 & 0.004 & $<0.001-0.009$ & 2.4 & 265 \\
\hline - Diabetes mellitus & 2.1 & 0.010 & $0.001-0.019$ & 3.6 & 265 \\
\hline - Thyroid disease & 1.8 & 0.012 & $0.002-0.023$ & 4.4 & 265 \\
\hline - Cardiac disease & 1.3 & 0.002 & $<0.001-0.005$ & 1.4 & 265 \\
\hline - Lung disease & 2.9 & 0.006 & $<0.001-0.012$ & 2.8 & 265 \\
\hline - Renal disease & 1.8 & 0.013 & $0.002-0.024$ & 4.7 & 265 \\
\hline - Digestive disease & 1.3 & 0.009 & $0.001-0.018$ & 3.3 & 265 \\
\hline - Hematological disease & 1.4 & 0.012 & $0.002-0.023$ & 4.7 & 265 \\
\hline - Neurological disease & 1.2 & 0.008 & $<0.001-0.016$ & 3.7 & 265 \\
\hline - Psychiatric disease & 1.4 & 0.022 & $0.005-0.038$ & 7.0 & 265 \\
\hline$\bullet \mathrm{HIV}$ & 1.3 & 0.006 & $<0.001-0.012$ & 2.6 & 265 \\
\hline - Other & 6.5 & 0.033 & $0.009-0.057$ & 11.8 & 265 \\
\hline
\end{tabular}


Table 2 Estimates of mean, intracluster correlation coefficients (ICC), their respective $95 \% \mathrm{Cl}$, design effect (Deff), and mean cluster size $\left(n_{a}\right)$ for numeric maternal characteristics

\begin{tabular}{|c|c|c|c|c|c|}
\hline Variable & Mean & ICC & $95 \% \mathrm{Cl}$ for ICC & Deff & $\mathrm{n}_{\mathrm{a}}$ \\
\hline Age (years) & 26.1 & 0.018 & $0.004-0.033$ & 5.3 & 265 \\
\hline Month stopped working & 6.9 & 0.015 & $<0.001-0.032$ & 2.6 & 99 \\
\hline Workload (hours daily) & 8.0 & 0.040 & $0.007-0.072$ & 6.9 & 98 \\
\hline Pre-pregnancy weight (Kg) & 62.1 & 0.021 & $0.005-0.038$ & 6.6 & 250 \\
\hline Height (m) & 1.6 & 0.041 & $0.011-0.071$ & 9.8 & 238 \\
\hline Final weight (Kg) & 73.2 & 0.022 & $0.005-0.040$ & 6.4 & 237 \\
\hline Weight gain in pregnancy (Kg) & 10.9 & 0.012 & $0.001-0.023$ & 4.5 & 229 \\
\hline Initial Body Mass Index $\left(\mathrm{Kg} / \mathrm{m}^{2}\right)$ & 24.4 & 0.012 & $0.001-0.024$ & 4.5 & 230 \\
\hline Final Body Mass Index (Kg/m²) & 28.7 & 0.016 & $0.002-0.030$ & 5.5 & 220 \\
\hline Number of pregnancies & 2.4 & 0.006 & $<0.001-0.013$ & 2.8 & 265 \\
\hline Number of vaginal deliveries & 0.8 & 0.005 & $<0.001-0.011$ & 2.5 & 265 \\
\hline Number of cesarean sections & 0.3 & 0.014 & $0.002-0.025$ & 4.7 & 265 \\
\hline Number of abortions & 0.3 & 0.006 & $<0.001-0.013$ & 2.3 & 265 \\
\hline Number of uterine curettage & 0.2 & 0.008 & $<0.001-0.015$ & 2.9 & 264 \\
\hline
\end{tabular}

confidence intervals, design effects and average cluster sizes were also objectives for this study and they are presented for more than 250 maternal and neonatal variables.

\section{Methods}

The Brazilian Multicenter Study on Preterm Birth consisted of a multicenter cross-sectional study plus a nested case-control study to assess their associated factors implemented in referral obstetrical units (clusters) from several states of the country. The full research proposal has already been published elsewhere [11].

A single-stage cluster sampling was used. Clusters were selected by an invitation to 27 healthcare institutions that build a national network called Brazilian
Network for Studies on Reproductive and Perinatal Health. They are located in the five geographical regions of the country, almost all of them are public institutions, and all of them receive both low and high risk pregnant women. Initially 26 centers accepted to participate, but 20 selected institutions were able to fully take part in the study.

The sample size was calculated using the official prevalence of preterm births in Brazil of around 6.5\% [12]. Considering an acceptable absolute difference of about $0.25 \%$ between the sample and the population prevalence, and a type I error of $5 \%$, initial surveillance of a sample size of 37,000 deliveries was necessary. For the case-control study component, the estimated sample size was 1,055 women in each group (cases and controls). The total

Table 3 Estimates of prevalence (P), intracluster correlation coefficients (ICC), their respective $95 \% \mathrm{Cl}$, design effect (Deff), and mean cluster size $\left(n_{a}\right)$ for maternal socio-demographic characteristics

\begin{tabular}{|c|c|c|c|c|c|}
\hline Variable & $\mathrm{P}(\%)$ & ICC & $95 \% \mathrm{Cl}$ for ICC & Deff & $\mathrm{n}_{\mathrm{a}}$ \\
\hline Household (rural) & 9.8 & 0.097 & $0.034-0.159$ & 32.9 & 264 \\
\hline Homeownership & 57.5 & 0.041 & $0.012-0.070$ & 15.2 & 265 \\
\hline Paved street & 78.7 & 0.181 & $0.077-0.286$ & 60.0 & 262 \\
\hline Piped water & 94.2 & 0.090 & $0.031-0.149$ & 30.0 & 263 \\
\hline Sewer & 86.8 & 0.191 & $0.083-0.300$ & 53.8 & 261 \\
\hline Family income (>US\$ 400.00) & 38.8 & 0.103 & $0.037-0.168$ & 28.8 & 244 \\
\hline Paid work & 42.6 & 0.036 & $0.010-0.063$ & 10.8 & 263 \\
\hline Paid work in pregnancy & 88.8 & 0.041 & $0.008-0.073$ & 7.4 & 112 \\
\hline Strenuous work & 43.4 & 0.037 & $0.006-0.068$ & 5.5 & 99 \\
\hline Standing work & 61.4 & 0.017 & $<0.001-0.034$ & 2.8 & 99 \\
\hline Night work & 19.5 & 0.033 & $0.004-0.061$ & 4.3 & 98 \\
\hline Housework (alone) & 50.7 & 0.019 & $0.004-0.034$ & 7.3 & 265 \\
\hline
\end{tabular}


Table 4 Estimates of prevalence (P), intracluster correlation coefficients (ICC), their respective $95 \% \mathrm{Cl}$, design effect (Deff), and mean cluster size $\left(\mathrm{n}_{\mathrm{a}}\right)$ for categorical variables of process during pregnancy

\begin{tabular}{|c|c|c|c|c|c|}
\hline Variable & $\mathrm{P}(\%)$ & ICC & $95 \% \mathrm{Cl}$ for ICC & Deff & $\mathrm{n}_{\mathrm{a}}$ \\
\hline \multicolumn{6}{|l|}{ Healthcare facility used for prenatal care: } \\
\hline - Primary health care unit & 71.3 & 0.117 & $0.044-0.191$ & 31.1 & 256 \\
\hline - Hospital & 34.3 & 0.185 & $0.079-0.291$ & 46.2 & 256 \\
\hline - Private clinic & 9.3 & 0.051 & $0.015-0.086$ & 15.9 & 256 \\
\hline - Other & 0.3 & 0.005 & $<0.001-0.011$ & 2.4 & 256 \\
\hline - Without prenatal care & 3.2 & 0.003 & $<0.001-0.008$ & 2.2 & 256 \\
\hline Prenatal care by physician & 89.7 & 0.195 & $0.085-0.305$ & 64.5 & 256 \\
\hline Start of prenatal care ( $1^{\text {st }}$ trimester $)$ & 64.8 & 0.034 & $0.009-0.059$ & 8.9 & 219 \\
\hline Number of prenatal care visits $(\geq 6)$ & 58.8 & 0.054 & $0.016-0.092$ & 13.7 & 231 \\
\hline Ultrasound during prenatal care & 98.4 & 0.001 & $<0.001-0.004$ & 1.4 & 254 \\
\hline Physical effort & 42.0 & 0.053 & $0.016-0.089$ & 14.8 & 263 \\
\hline Depression & 32.5 & 0.073 & $0.024-0.122$ & 26.2 & 263 \\
\hline Anxiety & 65.5 & 0.099 & $0.035-0.163$ & 38.0 & 263 \\
\hline Smoking & 13.5 & 0.020 & $0.004-0.036$ & 7.7 & 265 \\
\hline Use of alcohol & 15.9 & 0.031 & $0.008-0.054$ & 10.2 & 263 \\
\hline Illicit drugs use (during or before) & 4.9 & 0.015 & $0.002-0.027$ & 5.8 & 265 \\
\hline Vaginal discharge treatment (self-reported) & 36.6 & 0.010 & $0.001-0.020$ & 4.1 & 264 \\
\hline \multicolumn{6}{|l|}{ Vulvovaginitis: } \\
\hline - Bacterial vaginosis & 12.9 & 0.039 & $0.008-0.069$ & 11.1 & 160 \\
\hline - Candidiasis & 13.5 & 0.061 & $0.016-0.106$ & 11.2 & 160 \\
\hline - Trychomoniasis & 1.4 & 0.011 & $<0.001-0.023$ & 4.9 & 160 \\
\hline - Other vulvovaginitis & 0.9 & 0.030 & $0.005-0.054$ & 6.2 & 160 \\
\hline Vulvovaginitis treatment (registered) & 24.1 & 0.073 & $0.020-0.126$ & 15.1 & 164 \\
\hline Urinary infection treatment (self-reported) & 36.3 & 0.018 & $0.004-0.032$ & 6.7 & 261 \\
\hline Urinary infection (registered) & 32.9 & 0.032 & $0.008-0.057$ & 10.0 & 209 \\
\hline - Asymptomatic bacteriuria & 15.7 & 0.084 & $0.027-0.140$ & 23.2 & 184 \\
\hline - Cystitis & 7.1 & 0.028 & $0.006-0.050$ & 7.9 & 184 \\
\hline - Pyelonephritis & 2.0 & 0.003 & $<0.001-0.008$ & 2.0 & 184 \\
\hline Urinary treatment (registered) & 2.1 & 0.075 & $0.023-0.126$ & 18.2 & 184 \\
\hline Periodontal infection & 17.0 & 0.036 & $0.010-0.063$ & 14.5 & 262 \\
\hline Other infection & 9.1 & 0.019 & $0.004-0.035$ & 7.5 & 263 \\
\hline - Unknown fever & 1.8 & 0.024 & $0.006-0.043$ & 11.1 & 265 \\
\hline - Diarrhea fever & 0.9 & 0.006 & $<0.001-0.012$ & 3.2 & 265 \\
\hline - HIV - diagnosis in pregnancy & 0.6 & 0.002 & $<0.001-0.006$ & 2.1 & 265 \\
\hline - Pneumonia & 0.5 & $<0.001$ & $<0.001-0.003$ & 1.2 & 265 \\
\hline - Tuberculosis & $<0.1$ & $<0.001$ & $<0.001-0.003$ & 0.8 & 265 \\
\hline - Sinusitis/tonsillitis & 3.4 & 0.015 & $0.003-0.028$ & 6.7 & 265 \\
\hline - Hepatitis & 0.2 & 0.007 & $<0.001-0.014$ & 4.2 & 265 \\
\hline - Genital herpes & $<0.1$ & 0.001 & $<0.001-0.004$ & 1.4 & 265 \\
\hline - Toxoplasmosis & 0.5 & 0.009 & $<0$ 001-0.018 & 3.4 & 265 \\
\hline
\end{tabular}


Table 4 Estimates of prevalence $(\mathrm{P})$, intracluster correlation coefficients (ICC), their respective $95 \% \mathrm{Cl}$, design effect (Deff), and mean cluster size $\left(\mathbf{n}_{\mathrm{a}}\right)$ for categorical variables of process during pregnancy (Continued)

\begin{tabular}{|c|c|c|c|c|c|}
\hline Anemia & 29.2 & 0.046 & $0.013-0.078$ & 13.4 & 259 \\
\hline Iron replacement & 84.9 & 0.037 & $0.001-0.063$ & 12.1 & 264 \\
\hline Bleeding & 23.9 & 0.012 & $0.001-0.022$ & 4.6 & 264 \\
\hline - Bleeding in first trimester & 12.2 & 0.006 & $<0.001-0.013$ & 2.6 & 264 \\
\hline - Bleeding in second trimester & 6.7 & 0.002 & $<0.001-0.006$ & 1.6 & 264 \\
\hline - Bleeding in third trimester & 6.3 & 0.013 & $0.002-0.024$ & 6.1 & 264 \\
\hline
\end{tabular}

number of preterm births estimated to be followed in both components of the study was around 3,600.

The participating centers performed a prospective surveillance of all patients admitted to give birth in order to identify preterm births. For this purpose and according to standard international definitions, preterm birth was considered that occurring before 37 completed weeks of gestational age evaluated by an ultrasound scan performed early in pregnancy, by a known date of the last menstrual period, or alternatively by the evaluation of the somatic age of the newborn. During the first months of the study, in order to complete the sample for the appropriate analysis of the factors associated with spontaneous preterm birth, a random sample of women who had full-term birth was also selected.

Data was collected during six to twelve months for each center, from April 2011 to March 2012, in a detailed form called "Questionnaire" including 306 variables from four sources: interview with women in the postpartum period, medical records and prenatal chart of the mother (before hospital discharge), and newborn medical records (within sixty days after birth, even if it remained in hospital for longer period). An electronic system of data entry called OpenClinica ${ }^{\circ}$ was selected and a proper clinical research form (CRF) was designed for the input of data after the questionnaire of each case was completed and reviewed.

High quality data and reliable information was guaranteed by several steps: preparatory meetings, development of detailed manuals of operation, monitoring technical site visits to the centers, close monitoring of data collection and data entry, concurrent query management, checking for logical inconsistencies, and correction of database. The research proposal was firstly approved by the Institutional Review Board of the coordinating center and then confirmed by IRB of each other participating center.

\section{Data analysis}

In this study, each of the 20 participating centers (hospital) was considered a primary sampling unit (PSU) and there was no stratification of the PSU or weighting of the data.
The subject (unit of analysis) was woman who delivered preterm (case) or at term (control).

Estimated prevalence (categorical variables) or means (continuous numeric variables), intracluster correlation coefficients (ICC), their respective 95\% confidence intervals (CI), design effects (Deff) and mean cluster size of each variable were calculated. Software programs used for analysis were SPSS ${ }^{\oplus}$ version 20.0 [13] and Stata version 7.0 [14], taking into consideration the cluster sampling plan (centers) for data analysis.

According to Kish [2], ICC (Roh) is: $\rho=\left(s^{2}{ }_{a}-s^{2}{ }_{b} / b\right) / s^{\wedge}$, where $s_{a}^{2}$ is the variance between clusters; $s^{2}{ }_{b}$ is the variance within clusters, $\mathrm{b}$ is the size of clusters and $s^{\wedge}$ is the estimate of $S^{2}$ (variance in individual level). The estimate $s^{\wedge}$ is obtained by: $s^{\wedge}=s^{2}{ }_{a}+[(b-1) / b] s^{2}{ }_{b}$. Stata's equivalent computing formula for ICC [14] is: ICC $=[(F-1) a / n] / 1+$ $(F-1) a / n$, where ' $F$ ' is the Snedecor's $F$-value from the ANOVA table and 'a' is the number of groups. The variance estimate for ICC is obtained by an extensive asymptotic formula and because this it was not showed.

For this study, the Design effect - DEFF [2] is Deff= $\left.\operatorname{var}_{\text {actual }}(r) / \operatorname{var}_{\mathrm{SRS}}(r)=s^{2} a / a / s^{2} / n\right)$ where $\operatorname{var}_{\text {actual }}(\mathrm{r})$ is the estimated variance according to the complex design being studied and $\operatorname{var}_{\text {SRS }}(r)$ is the variance in the estimator considering the design as if it were calculated using a SRS of the same size, $n$.

\section{Results}

During fifteen months, 5,296 births were included in the study, 4,150 of them being preterm births (1,491 due to spontaneous preterm labor, 1,191 due to a prelabor premature rupture of membranes and 1,468 due to a therapeutic interruption of pregnancy either for a maternal or fetal condition) and a sample of 1,146 term births to be used as controls for the case-control component.

Clustering was not stratified by region. Proportionally more centers were located in the Southeast of the country and consequently over half of births were from this region $(11 / 20-53.5 \%)$. The other centers were from Northeast region $(7 / 20-35 \%)$, contributing with $34.8 \%$ of births studied, South region (2/20 - 10\%), with $11.7 \%$ of births. The mean size of each cluster was 265 cases. 
Table 5 Estimates of prevalence (P), intracluster correlation coefficients (ICC), their respective $95 \% \mathrm{Cl}$, design effect (Deff), and mean cluster size $\left(\mathrm{n}_{\mathrm{a}}\right)$ for categorical variables of process during pregnancy

\begin{tabular}{|c|c|c|c|c|c|}
\hline Variable & $\mathrm{P}(\%)$ & ICC & $95 \% \mathrm{Cl}$ for ICC & Deff & $\mathrm{n}_{\mathrm{a}}$ \\
\hline Hospitalization & 22.3 & 0.030 & $0.008-0.052$ & 10.0 & 265 \\
\hline \multicolumn{6}{|l|}{ Reasons for hospitalization: } \\
\hline - Emesis & 0.6 & 0.006 & $0.001-0.013$ & 2.3 & 264 \\
\hline - Uterine contraction & 5.7 & 0.014 & $0.002-0.026$ & 5.3 & 264 \\
\hline - Amniorrhexis & 2.2 & 0.009 & $0.001-0.017$ & 4.0 & 264 \\
\hline - Bleeding & 2.6 & 0.008 & $<0.001-0.016$ & 3.0 & 264 \\
\hline - Maternal disease & 8.9 & 0.029 & $0.007-0.050$ & 10.1 & 264 \\
\hline - Fetal disease & 0.8 & 0.028 & $0.007-0.049$ & 6.0 & 264 \\
\hline Syphilis & 1.6 & 0.004 & $<0.001-0.009$ & 1.7 & 265 \\
\hline Anemia (registered) & 32.0 & 0.070 & $0.023-0.118$ & 24.1 & 238 \\
\hline Treatment for anemia & 52.6 & 0.283 & $0.138-0.428$ & 74.8 & 213 \\
\hline Short cervix (US) & 1.4 & 0.011 & $<0.001-0.022$ & 4.0 & 209 \\
\hline Cervical insufficiency & 2.1 & 0.005 & $<0.001-0.012$ & 2.6 & 230 \\
\hline Cerclage & 1.4 & 0.019 & $0.003-0.034$ & 5.6 & 238 \\
\hline Uterine anomalies & 0.6 & $<0.001$ & $<0.001-0.003$ & 0.6 & 237 \\
\hline Fibroid & 1.9 & 0.002 & $<0.001-0.006$ & 1.5 & 233 \\
\hline \multicolumn{6}{|l|}{ Maternal diseases: } \\
\hline - Diabetes & 5.7 & 0.027 & $0.006-0.047$ & 7.8 & 254 \\
\hline - Gestational hypertension & 7.7 & 0.025 & $0.006-0.045$ & 9.4 & 254 \\
\hline - Preeclampsia/eclampsia/HELLP & 16.2 & 0.062 & $0.019-0.104$ & 22.5 & 254 \\
\hline - Chronic hypertension & 5.7 & 0.007 & $<0.001-0.014$ & 2.8 & 254 \\
\hline - Other chronic infection & 0.7 & 0.010 & $0.001-0.020$ & 4.5 & 254 \\
\hline - Thyroid diseases & 1.6 & 0.027 & $0.006-0.047$ & 8.2 & 254 \\
\hline - Renal disease & 1.2 & 0.008 & $<0.001-0.015$ & 3.1 & 254 \\
\hline - Sickle cell anemia & 0.3 & 0.002 & $<0.001-0.006$ & 1.5 & 254 \\
\hline - Other chronic anemia & 0.5 & $<0.001$ & $<0.001-0.003$ & 0.7 & 254 \\
\hline - Cardiac disease & 1.1 & 0.003 & $<0.001-0.008$ & 1.9 & 254 \\
\hline - Lung disease & 1.5 & 0.009 & $<0.001-0.017$ & 3.8 & 254 \\
\hline - Epilepsy & 0.6 & 0.001 & $<0.001-0.004$ & 1.5 & 254 \\
\hline - Systemic lupus erythematous & 0.5 & 0.020 & $0.004-0.036$ & 4.6 & 254 \\
\hline - Other collagenoses & 0.2 & 0.001 & $<0.001-0.004$ & 1.4 & 254 \\
\hline - Digestive disease & 0.6 & 0.006 & $<0.001-0.013$ & 3.1 & 254 \\
\hline - Bariatric surgery & $<0.1$ & $<0.001$ & $<0.001-0.003$ & 0.8 & 254 \\
\hline - Psychiatric disease & 1.0 & 0.015 & $0.003-0.028$ & 5.4 & 254 \\
\hline - Orthopedic disease & 0.2 & $<0.001$ & $<0.001-0.003$ & 0.9 & 254 \\
\hline - Neoplasms & 0.2 & 0.001 & $<0.001-0.004$ & 1.4 & 254 \\
\hline - Thrombosis or thrombophilia & 0.4 & 0.006 & $<0.001-0.013$ & 2.4 & 254 \\
\hline Fetal malformation & 5.5 & 0.146 & $0.057-0.236$ & 35.9 & 246 \\
\hline Fetal growth restriction & 9.3 & 0.019 & $0.004-0.035$ & 6.9 & 246 \\
\hline Other fetal morbidity & 7.4 & 0.386 & $0.219-0.554$ & 101.5 & 246 \\
\hline Triplets & 2.0 & $<0.001$ & $<0.001-0.030$ & 1.0 & 22 \\
\hline Infertility treatment & 4.4 & $<0.001$ & $<0.001-0.031$ & 0.9 & 22 \\
\hline
\end{tabular}


Table 5 Estimates of prevalence (P), intracluster correlation coefficients (ICC), their respective $95 \% \mathrm{Cl}$, design effect (Deff), and mean cluster size $\left(n_{a}\right)$ for categorical variables of process during pregnancy (Continued)

\begin{tabular}{lcccc}
\hline Multiple monochorionic pregnancy & 35.8 & 0.046 & $<0.001-0.111$ & 2.0 \\
Multiple monoamniotic pregnancy & 5.8 & 0.038 & $<0.001-0.098$ & 18 \\
Twin-to-twin transfusion syndrome & 5.4 & $<0.001$ & $<0.001-0.036$ & 18 \\
\hline
\end{tabular}

Table 6 Estimates of prevalence (P), intracluster correlation coefficients (ICC), their respective $95 \% \mathrm{Cl}$, design effect (Deff), and mean cluster size $\left(n_{a}\right)$ for categorical variables of process during labor

\begin{tabular}{|c|c|c|c|c|c|}
\hline Variable & $\mathrm{P}(\%)$ & ICC & $95 \% \mathrm{Cl}$ for ICC & Deff & $\mathrm{n}_{\mathrm{a}}$ \\
\hline Mode of onset of labor (spontaneous) & 55.3 & 0.018 & $0.004-0.032$ & 6.5 & 265 \\
\hline Intrapartum antibiotic (ATB) & 51.8 & 0.194 & $0.084-0.304$ & 71.8 & 260 \\
\hline - ATB for fever & 0.5 & 0.003 & $<0.001-0.008$ & 1.8 & 252 \\
\hline - ATB for GBS colonization & 1.9 & 0.019 & $0.004-0.034$ & 5.6 & 252 \\
\hline - ATB for risk factor to GBS & 20.0 & 0.148 & $0.058-0.238$ & 48.2 & 252 \\
\hline - ATB for other reasons & 29.1 & 0.384 & $0.217-0.550$ & 148.0 & 252 \\
\hline \multicolumn{6}{|l|}{ Analgesics during labor: } \\
\hline - Epidural & 4.2 & 0.200 & $0.087-0.313$ & 43.3 & 259 \\
\hline - Epidural plus spinal anesthesia & 3.7 & 0.201 & $0.088-0.314$ & 74.3 & 259 \\
\hline - Spinal anesthesia & 20.1 & 0.338 & $0.181-0.495$ & 112.8 & 259 \\
\hline - Meperidine & 0.8 & 0.018 & $0.004-0.033$ & 6.6 & 259 \\
\hline - Tramadol & 0.2 & 0.002 & $<0.001-0.006$ & 1.4 & 259 \\
\hline - Benzodiazepines & 0.1 & 0.008 & $<0.001-0.017$ & 3.6 & 259 \\
\hline - Antispasmodics & 2.2 & 0.071 & $0.023-0.119$ & 21.2 & 259 \\
\hline - Oral analgesics & 2.0 & 0.091 & $0.031-0.150$ & 23.0 & 259 \\
\hline - Other analgesics & 2.4 & 0.102 & $0.036-0.168$ & 46.6 & 259 \\
\hline Mode of delivery (vaginal) & 48.8 & 0.024 & $0.006-0.043$ & 7.7 & 265 \\
\hline Episiotomy & 38.7 & 0.176 & $0.068-0.283$ & 31.5 & 126 \\
\hline Forceps & 3.9 & 0.056 & $0.014-0.099$ & 12.9 & 116 \\
\hline \multicolumn{6}{|l|}{ Cesarean indication: } \\
\hline - Fetal distress & 25.7 & 0.016 & $0.001-0.031$ & 3.8 & 133 \\
\hline - Cephalic-pelvic disproportion & 2.8 & 0.016 & $0.001-0.032$ & 3.2 & 133 \\
\hline - Two or more cesarean scars & 9.8 & 0.006 & $<0.001-0.014$ & 2.0 & 133 \\
\hline - Pelvic or other abnormal fetal presentation & 15.6 & 0.012 & $<0.001-0.025$ & 2.9 & 133 \\
\hline - Functional dystocia & 2.2 & 0.022 & $0.003-0.041$ & 3.8 & 133 \\
\hline - Diabetes & 1.8 & 0.013 & $<0.001-0.027$ & 3.3 & 133 \\
\hline - Arterial hypertension & 22.7 & 0.043 & $0.011-0.075$ & 7.4 & 133 \\
\hline - Cardiac disease & 0.6 & 0.009 & $<0.001-0.020$ & 1.6 & 133 \\
\hline$\bullet \mathrm{HIV}$ & 1.6 & 0.005 & $<0.001-0.012$ & 1.7 & 133 \\
\hline - Placenta previa & 2.0 & 0.006 & $<0.001-0.014$ & 1.6 & 133 \\
\hline - Abruptio placentae & 4.8 & 0.005 & $<0.001-0.013$ & 1.9 & 133 \\
\hline - Uterine rupture & 0.1 & 0.006 & $<0.001-0.015$ & 1.1 & 133 \\
\hline - Fetal malformation & 3.2 & 0.133 & $0.051-0.215$ & 18.9 & 133 \\
\hline - Fetal macrosomia & 1.7 & 0.002 & $<0.001-0.008$ & 1.4 & 133 \\
\hline - Maternal choice & 1.0 & 0.037 & $0.008-0.065$ & 7.2 & 133 \\
\hline - Other & 17.1 & 0.082 & $0.027-0.137$ & 14.9 & 133 \\
\hline Type of incision (segmental transverse) & 96.3 & 0.193 & $0.081-0.304$ & 13.5 & 126 \\
\hline
\end{tabular}




\section{Estimated ICCs}

Estimated ICCs are presented in Tables 1, 2, 3, 4, 5, 6, 7, 8, 9 and 10 for each of 261 variables. Tables 2 and 8 show results for continuous numeric variables, while other tables present results for categorical variables or were categorized for analysis. In addition to ICC, the $95 \%$ confidence interval (CI), the design effect (Deff) and the mean cluster size $\left(n_{a}\right)$, as well as the estimated prevalence (or mean) are presented. ICC ranged from $<0.001$ to 0.965 , with a median of 0.028 . ICC was $<0.1$ in $78.5 \%$ of the variables and $<0.3$ for $95 \%$ of them.

Tables 1 and 2 presents some variables related to maternal characteristics, including clinical and obstetrical history. ICCs ranged from $<0.001$ to 0.145 (median 0.011). Table 3 shows the socio-demographic variables studied, and ICC ranged from 0.017 to 0.191 (median 0.041). Tables 4 and 5 presents variables related to pregnancy characteristics with ICC ranging from 0.001 to 0.386 (median 0.015). The variables related to labor conditions were presented in Table 6. It can be observed that ICC ranged from 0.002 to 0.384 , with a median of 0.022 . Tables 7 and 8 shows variables related to perinatal outcomes and ICC were $<0.1$ in $81 \%$ of them. The most important outcome variable, newborn morbidities, is presented in Table 7. Tables 9 and 10 present some variables analyzed specifically for preterm births and are related to management. Most variables in Table 9 showed ICC greater than 0.3 and the greatest ICC of this study $(0.965)$ was relative to the variable "corticosteroids use", a management aspect well defined and well-established in all obstetric protocols, so there were high degree of homogeneity in clusters in these variables. The median of ICCs was 0.274 . The median ICC in Table 10 was 0.079 .

Table 7 Estimates of prevalence (P), intracluster correlation coefficients (ICC), their respective $95 \% \mathrm{Cl}$, design effect (Deff), and mean cluster size $\left(n_{a}\right)$ for categorical newborn outcome variables

\begin{tabular}{|c|c|c|c|c|c|}
\hline Variable & $\mathrm{P}(\%)$ & ICC & $95 \% \mathrm{Cl}$ for ICC & Deff & $\mathrm{n}_{\mathrm{a}}$ \\
\hline Diagnosis of gestational age (US) & 45.4 & 0.264 & $0.128-0.399$ & 84.8 & 265 \\
\hline Stillborn & 3.1 & 0.026 & $0.006-0.046$ & 7.5 & 265 \\
\hline Intubation at delivery & 13.4 & 0.013 & $0.002-0.024$ & 4.1 & 248 \\
\hline Use of surfactant & 12.6 & 0.015 & $0.002-0.027$ & 4.4 & 245 \\
\hline Fetal malformation & 9.5 & 0.078 & $0.026-0.130$ & 19.6 & 246 \\
\hline Ventilatory support & 42.6 & 0.041 & $0.011-0.070$ & 15.1 & 249 \\
\hline Neonatal morbidity & 60.3 & 0.126 & $0.047-0.205$ & 33.4 & 248 \\
\hline - Sepsis & 27.7 & 0.051 & $0.011-0.091$ & 8.3 & 144 \\
\hline - Respiratory distress & 73.4 & 0.061 & $0.014-0.107$ & 9.9 & 148 \\
\hline - Pneumothorax & 3.6 & 0.041 & $0.007-0.075$ & 8.2 & 141 \\
\hline - Cerebral hemorrhage (1-4) & 8.7 & 0.052 & $0.007-0.097$ & 5.8 & 114 \\
\hline - Lung hemorrhage & 3.7 & 0.028 & $0.004-0.053$ & 5.7 & 143 \\
\hline - Hematologic dysfunction & 51.0 & 0.267 & $0.116-0.417$ & 71.7 & 146 \\
\hline - Endocrine dysfunction & 22.0 & 0.119 & $0.036-0.201$ & 30.3 & 145 \\
\hline - Renal dysfunction & 6.4 & 0.013 & $<0.001-0.027$ & 3.5 & 145 \\
\hline - Immune dysfunction & 6.5 & 0.092 & $0.025-0.158$ & 22.1 & 145 \\
\hline - Musculoskeletal morbidity & 8.6 & 0.190 & $0.071-0.310$ & 38.4 & 146 \\
\hline - Gastrointestinal dysfunction & 43.2 & 0.340 & $0.168-0.512$ & 70.6 & 146 \\
\hline - Hypovolemia & 10.4 & 0.026 & $0.003-0.049$ & 6.0 & 146 \\
\hline - Necrotizing enterocolitis & 2.4 & 0.020 & $0.001-0.038$ & 3.2 & 145 \\
\hline - Convulsion/anticonvulsants & 4.8 & 0.039 & $0.007-0.071$ & 6.7 & 146 \\
\hline - Vasoactive amines & 12.2 & 0.019 & $0.001-0.037$ & 3.5 & 146 \\
\hline - Pneumonia & 5.6 & 0.118 & $0.036-0.200$ & 15.6 & 145 \\
\hline - Oxygen therapy with 28 days & 8.0 & 0.021 & $0.002-0.041$ & 3.8 & 145 \\
\hline - Oxygen therapy with 56 days & 2.9 & 0.012 & $<0.001-0.025$ & 2.8 & 143 \\
\hline - Degree of retinopathy (1-3) & 4.8 & 0.028 & $<0.001-0.056$ & 4.2 & 99 \\
\hline Condition at discharge (live) & 91.8 & 0.014 & $0.002-0.026$ & 4.1 & 252 \\
\hline
\end{tabular}


Table 8 Estimates of mean, intracluster correlation coefficients (ICC), their respective $95 \% \mathrm{Cl}$, design effect (Deff), and mean cluster size $\left(n_{a}\right)$ for numeric newborn outcome variables

\begin{tabular}{|c|c|c|c|c|c|}
\hline Variable & Mean & ICC & $95 \% \mathrm{Cl}$ for ICC & Deff & $\mathrm{n}_{\mathrm{a}}$ \\
\hline Gestational age (weeks) & 34.5 & 0.031 & $0.008-0.055$ & 10.4 & 265 \\
\hline Birth weight (g) & 2321.1 & 0.033 & $0.009-0.058$ & 11.6 & 264 \\
\hline Birth weight $2^{\circ}$ twin (g) & 1905.2 & 0.007 & $<0.001-0.043$ & 1.4 & 21 \\
\hline APGAR $1^{\text {st }}$ minute & 7.3 & 0.032 & $0.008-0.056$ & 8.6 & 261 \\
\hline APGAR $1^{\text {st }}$ minute $2^{\circ}$ twin & 6.7 & 0.042 & $<0.001-0.098$ & 2.2 & 21 \\
\hline APGAR $5^{\text {th }}$ minute & 8.6 & 0.041 & $0.012-0.070$ & 11.5 & 261 \\
\hline APGAR $5^{\text {th }}$ minute $2^{\circ}$ twin & 8.3 & 0.002 & $<0.001-0.034$ & 1.1 & 21 \\
\hline Head circumference (cm) & 31.7 & 0.031 & $0.008-0.055$ & 10.1 & 236 \\
\hline Head circumference $2^{\circ}$ twin $(\mathrm{cm})$ & 30.8 & 0.018 & $<0.001-0.067$ & 1.1 & 18 \\
\hline Stature $(\mathrm{cm})$ & 44.3 & 0.031 & $0.007-0.054$ & 10.3 & 237 \\
\hline Stature $2^{\circ}$ twin $(\mathrm{cm})$ & 42.3 & 0.025 & $<0.001-0.077$ & 1.4 & 18 \\
\hline Length of ICU stay (days) & 8.4 & 0.088 & $0.028-0.148$ & 21.4 & 220 \\
\hline Length of hospital stay (days) & 13.3 & 0.037 & $0.009-0.065$ & 8.5 & 235 \\
\hline Age of newborn at sepsis (days) & 4.6 & 0.173 & $0.054-0.292$ & 7.2 & 39 \\
\hline Age of newborn at death (days) & 8.9 & 0.088 & $<0.001-0.179$ & 2.7 & 17 \\
\hline
\end{tabular}

Table 9 Estimates of prevalence (P), intracluster correlation coefficients (ICC), their respective $95 \% \mathrm{Cl}$, design effect (Deff), and mean cluster size $\left(n_{a}\right)$ for categorical management variables in spontaneous labor conditions or preterm due to pPROM

\begin{tabular}{|c|c|c|c|c|c|}
\hline Variable & $\mathrm{P}(\%)$ & ICC & $95 \% \mathrm{Cl}$ for ICC & Deff & $\mathrm{n}_{\mathrm{a}}$ \\
\hline \multicolumn{6}{|l|}{ Preterm birth due to spontaneous labor: } \\
\hline Use of corticosteroids & 28.5 & 0.032 & $0.002-0.062$ & 5.2 & 73 \\
\hline Corticosteroids (betamethasone) & 86.4 & 0.851 & $0.754-0.948$ & 18.8 & 21 \\
\hline Use of tocolytic agents & 23.6 & 0.068 & $0.015-0.121$ & 8.7 & 72 \\
\hline Association of tocolytic agents & 9.9 & 0.368 & $0.167-0.570$ & 8.4 & 17 \\
\hline Therapeutic failure of tocolysis & 11.4 & 0.165 & $0.029-0.301$ & 4.3 & 17 \\
\hline Use of magnesium sulphate (neuroprotection) & 3.9 & 0.070 & $0.016-0.125$ & 9.3 & 70 \\
\hline Use of antibiotics & 42.8 & 0.262 & $0.117-0.407$ & 28.8 & 72 \\
\hline Intravenous antibiotic & 93.3 & 0.321 & $0.127-0.515$ & 10.1 & 31 \\
\hline Association of antibiotic & 15.3 & 0.144 & $0.025-0.263$ & 12.9 & 30 \\
\hline Group B streptococcus screening & 24.3 & 0.286 & $0.131-0.442$ & 26.2 & 65 \\
\hline \multicolumn{6}{|l|}{ Preterm birth due to pPROM: } \\
\hline Use of corticosteroids & 40.5 & 0.042 & $0.002-0.083$ & 3.7 & 53 \\
\hline Corticosteroids (betamethasone) & 85.0 & 0.965 & $0.941-0.990$ & 23.5 & 21 \\
\hline Use of tocolytic agents & 17.7 & 0.547 & $0.364-0.729$ & 38.3 & 56 \\
\hline Use of antibiotics & 78.2 & 0.233 & $0.095-0.371$ & 18.3 & 54 \\
\hline Intravenous antibiotic & 91.0 & 0.366 & $0.180-0.552$ & 14.4 & 41 \\
\hline Association of antibiotic & 20.9 & 0.245 & $0.093-0.397$ & 20.1 & 41 \\
\hline Group B streptococcus screening & 36.3 & 0.441 & $0.260-0.622$ & 27.9 & 50 \\
\hline Hydration solution (saline) & 11.0 & 0.419 & $0.235-0.602$ & 20.1 & 52 \\
\hline
\end{tabular}


Table 10 Estimates of prevalence (P), intracluster correlation coefficients (ICC), their respective $95 \% \mathrm{Cl}$, design effect (Deff), and mean cluster size $\left(n_{a}\right)$ for diagnosis and management among categorical variables related to therapeutic preterm delivery

\begin{tabular}{|c|c|c|c|c|c|}
\hline Variable & $\mathrm{P}(\%)$ & ICC & $95 \% \mathrm{Cl}$ for ICC & Deff & $\mathbf{n}_{\mathrm{a}}$ \\
\hline Therapeutic delivery for maternal disease & 74.6 & 0.102 & $0.032-0.172$ & 9.6 & 73 \\
\hline Therapeutic delivery for fetal disease & 54.1 & 0.065 & $0.016-0.115$ & 7.0 & 73 \\
\hline \multicolumn{6}{|c|}{ Maternal disease responsible for interruption of pregnancy: } \\
\hline - Diabetes & 7.3 & 0.063 & $0.011-0.115$ & 5.5 & 54 \\
\hline - Gestational hypertension & 12.9 & 0.144 & $0.048-0.240$ & 9.4 & 54 \\
\hline - Chronic hypertension & 15.3 & 0.009 & $<0.001-0.027$ & 1.8 & 54 \\
\hline - Preeclampsia & 58.2 & 0.079 & $0.017-0.140$ & 5.4 & 54 \\
\hline - Eclampsia & 3.2 & 0.017 & $<0.001-0.041$ & 1.8 & 54 \\
\hline • HELLP syndrome & 9.4 & 0.012 & $<0.001-0.031$ & 1.2 & 54 \\
\hline - Abruptio placentae & 7.7 & 0.009 & $<0.001-0.026$ & 1.6 & 54 \\
\hline - Previous placentae & 3.3 & 0.001 & $<0.001-0.013$ & 0.8 & 54 \\
\hline \multicolumn{6}{|l|}{ Fetal disease responsible for interruption of pregnancy: } \\
\hline - Fetal distress & 32.6 & 0.052 & $0.010-0.095$ & 6.1 & 71 \\
\hline - Fetal growth restriction & 19.8 & 0.037 & $0.004-0.069$ & 4.4 & 71 \\
\hline - Malformation & 5.2 & 0.144 & $0.052-0.236$ & 13.5 & 71 \\
\hline - Other fetal condition & 15.1 & 0.161 & $0.061-0.262$ & 15.8 & 71 \\
\hline \multicolumn{6}{|l|}{ Exams to evaluate fetal condition: } \\
\hline - Cardiotocography & 61.0 & 0.299 & $0.148-0.451$ & 23.7 & 67 \\
\hline - Dopplerfluxometry & 61.1 & 0.159 & $0.059-0.260$ & 14.4 & 67 \\
\hline - Fetal biophysical profile & 32.2 & 0.508 & $0.331-0.686$ & 43.5 & 67 \\
\hline - Fetal movements control & 4.3 & 0.101 & $0.030-0.172$ & 12.3 & 67 \\
\hline - Other exam & 12.9 & 0.041 & $0.005-0.077$ & 4.1 & 67 \\
\hline \multicolumn{6}{|l|}{ Determinant exams for diagnosis: } \\
\hline - Cardiotocography & 23.2 & 0.104 & $0.032-0.176$ & 10.1 & 70 \\
\hline - Dopplerfluxometry & 29.8 & 0.064 & $0.014-0.113$ & 6.4 & 70 \\
\hline - Fetal biophysical profile & 14.6 & 0.290 & $0.142-0.438$ & 24.0 & 70 \\
\hline - Fetal echocardiography & 1.2 & 0.030 & $0.001-0.058$ & 4.6 & 70 \\
\hline - Maternal hepatic dysfunction & 15.9 & 0.194 & $0.079-0.308$ & 19.9 & 70 \\
\hline - Maternal hematologic dysfunction & 21.0 & 0.278 & $0.134-0.423$ & 29.9 & 70 \\
\hline • Other & 41.2 & 0.102 & $0.031-0.173$ & 10.0 & 70 \\
\hline Maternal or fetal attempted treatment & 57.9 & 0.056 & $0.012-0.101$ & 5.7 & 71 \\
\hline Use of corticosteroids & 42.6 & 0.059 & $0.012-0.105$ & 6.2 & 70 \\
\hline Maternal condition at hospital discharge (cured) & 24.8 & 0.153 & $0.057-0.249$ & 15.7 & 73 \\
\hline
\end{tabular}

\section{Estimated deffs}

Estimated Deffs are presented in Tables 1, 2, 3, 4, 5, $6,7,8,9$ and 10 for each of 261 variables. Deff ranged from 0.6 to 148.0 , with a median of 6.1.

Deff were under 5.0 in $74 \%$ of variables in Tables 1 and 2, ranging from 1.2 to 42.2 (median 3.65). Table 3 presents Deff values ranging from 2.8 to 60 (median 13.0). In variables related to gestational process (Tables 4 and 5), Deff values ranged from 0.6 to
101.5 (median 4.9). The variables related to labor conditions (Table 6) showed Deff ranging from 1.1 to 148 (median 6.6), with $60 \%$ of them under 8.0. In Tables 7 and 8, related to perinatal outcomes, Deff values ranged from 1.1 to 84.8 (median 7.8). Tables 9 and 10 presented Deff median of 16.35 and 7.0, respectively.

We can observe that greater Deff median is present in process variables (Table 9), and greater ICCs. 


\section{Discussion}

This study presents a large number of intracluster correlation coefficients whose values can be considered low (close to zero) in most variables, showing intracluster heterogeneity.

The greater ICC values were found in process variables, especially management in spontaneous preterm labor conditions, as corticosteroids use, Group B streptococcus screening, use of tocolytic agents and use of antibiotic. Indeed, the mean ICC value for these variables was 10 times higher than the mean ICC of the study. The variable with the highest ICC was "corticosteroids - betamethasone", with a value of 0.965 . The prevalence of this variable was $85 \%$, showing a high degree of homogeneity in this management for preterm labor. These findings are in accordance with the literature that describes ICC values generally higher for variables related to process compared to those variables related to outcome $[15,16]$.

In the field of maternal and perinatal healthcare, Taljaard et al. calculated ICC values based on data obtained from secondary/tertiary services [16]. Comparing with our study, they found an overall median ICC of 0.067 versus 0.028 . For maternal and newborn outcome variables, their median ICCs was 0.011 (versus 0.014), and 0.054 (versus 0.041), respectively. The findings of those investigators showed that, for variables associated to process, ICC values tend to be $>0.07$. The present findings are in agreement with this observation.

Pagel et al. [17] estimated ICC for a range of outcomes using data from five community-based clusters randomized controlled trials in three low-income countries. Estimated ICC values for mortality outcomes were lower than those for process outcomes, with narrower confidence intervals throughout for trials with larger number of clusters.

All comparisons show that the smaller the cluster size, the higher the ICC and the opposite occurs regarding the prevalence of the condition. Estimates of intracluster correlation are much less reliable for rare outcomes and the size of the cluster had a greater impact than the number of clusters on the reliability of estimates for rare outcomes [17].

Furthermore, higher healthcare levels tend to increase the degree of homogeneity $[18,19]$. The size of ICC increases if the ICC represents data from secondary rather than primary care. This may be a reflection of the underlying heterogeneity of the datasets under consideration as the conditions represented across the different datasets were diverse. Although numerically small (average 0.01 ), such differences can have a substantial effect on sample size, even when the average of cluster is small [15]. The clusters in this study are secondary and tertiary hospitals, most of them are teaching hospitals, with the majority of procedures performed in conformity with evidence-based healthcare protocols.

Stratified randomization had the effect of reducing estimates of cluster correlation [15]. However, in the same way that in Brazilian Network for Surveillance of Severe Maternal Morbidity Study [20], which found ICC values close to zero, the selection of clusters did not performed stratification by region. The distribution of centers in this study, with almost half located in southeast region, is in accordance with the actual distribution of healthcare institutions and the proportionality of births per region in the country [21,22].

The large number of intracluster correlation coefficients presented in this study, considered low (close to zero) in most of variables, can probably be seen as a good parameter of variance for calculating sample size in new studies in the field of perinatal and maternal health [15].

We can, however, to identify some possible limitations of the study, including the fact that we used a nonprobabilistic sample from the centers (hospitals). Therefore, strictly speaking, the findings cannot be generalized to other populations. However, the majority of hospitals included in the study was third level referral hospitals taking care of high risk pregnancies and preterm babies. Probably the results would be applicable to other centers with such characteristics, irrespective of being private or public, especially in middle income countries like Brazil.

\section{Conclusions}

The Brazilian Multicenter Study on Preterm Birth, developed as part of the Brazilian Network for Studies on Reproductive and Perinatal Health, to the best of our knowledge is the first cross sectional multicenter study on this topic in the country. It represents a planned comprehensive assessment of preterm birth in Brazil and ICC values calculation and analysis of more than 250 maternal and newborn variables, showed heterogeneity of data in selected clusters. These findings increase reliability of study estimates and allow the use of these results to calculate the required sample size for future research studies in maternal and perinatal health.

\section{Abbreviations \\ CRF: Clinical research form; Deff: Design effect; ICC: Intraclass correlation coefficient; SRS: Simple random sampling.}

\section{Competing interests}

The authors declare that they have no competing interests.

\section{Authors' contributions}

The idea for the study first arose in a discussion among RPJ, JGC and RPT and then was developed and implemented by the whole research team. The first version of the manuscript was drafted by GJL and SMH, and then complemented with the suggestions of the others. RPJ and JGC supervised the entire process. All authors contributed to the development of the study protocol and approved the final version of manuscript. 


\section{Acknowledgements}

The authors thank the CNPq (Brazilian National Research Council) and Fapesp (Foundation for Support to Research of the State of Sao Paulo) for the financial sponsorship of this study, Process Fapesp 2009/53245-5 (Call AP.PPSUS-1). This publication was also sponsored by Fapesp (Processo 2014/08183-0)

The Brazilian Multicenter Study on Preterm Birth study group: Sergio T Marba, Ruth Guinsburg, Francisco E Martinez, Vilma Zotarelli, Lucio T Gurgel, Francisco E Feitosa, George N Chaves, Ana M Porto, Isabela C Coutinho, Antonio C Barbosa Lima, Elias F Melo Jr, Débora F Leite, Melania M Amorim, Adriana SO Melo, Fabiana O Melo, Marília G Martins, Marynea V Nunes, Cláudio S Paiva, Moises D Lima, Djacyr M Freire, Edson G Tristão, Denis Nascimento, Renato T Souza, Carlos A Menezes, Marcelo Aquino, Janete Vettorazzi, Cintia E Senger, Augusta MB Assumpção, Marcela AF Guedes, Maria EL Moreira, Vera T Borges, Nelson L Maia Filho, Jacinta P Mathias, Eduardo Souza, Ana CP Zamarian, Silvana M Quintana, Patrícia PS Melli, Fátima A Lotufo, Kaliane Uzilin, Elvira A Zanette, Carla B Andreucci, Tenilson A Oliveira, Laércio R Oliveira, Nelson Sass, Mirian RF Silveira, Pedro R Coutinho, Luciana Siqueira.

\section{Author details}

'Department of Obstetrics and Gynecology, School of Medical Sciences, University of Campinas, Campinas, Brazil. ${ }^{2}$ Center for Studies in Reproductive Health of Campinas (Cemicamp), Campinas, Brazil.

Received: 27 November 2013 Accepted: 14 April 2014 Published: 22 April 2014

\section{References}

1. Ukoumunne OC, Gulliford MC, Chinn S, Sterne JA, Burney PG: Methods for evaluating area-wide and organisation-based interventions in health and health care: a systematic review. Health Technol Assess 1999, 3(5):iii-92.

2. Kish L: Survey sampling. New York: John Wiley \& Sons; 1965.

3. Donner A, Koval JJ: Design considerations in the estimation of the intraclass correlation. Ann Hum Genet 1982, 46:271-277.

4. Campbell MK, Grimshaw JM, Elbourne DR: Intracluster correlation coefficients in cluster randomised trials: empirical insights into how should they be reported. BMC Med Res Methodol 2009, 4:9

5. Killip S, Mahfoud Z, Pearce K: What is an intracluster correlation coefficient? Crucial concepts for primary care researchers. Ann Fam Med 2004, 2:204-208.

6. Adams G, Gulliford MC, Ukoumunne OC, Eldridge S, Chinn S, Campbell MJ: Patterns of intra-cluster correlation from primary care research to inform study design and analysis. J Clin Epidemiol 2004, 57:785-794.

7. Hayes R, Moulton LH: Cluster Randomised Controlled Trials. New York: Chapman \&Hall/CRC Press; 2009.

8. US Census Bureau: Technical paper 63RV: current population survey design and methodology. TP63RV 2002, 14-18. Available at http://www.census.gov/prod/2002pubs/tp63rv.pdf. Accessed on October 02, 2013.

9. Hayes RJ, Benett S: Simple size calculation for cluster-randomised trials. Int J Epidemiol 1999, 28(2):319-326.

10. Eldridge SM, Ukoumunne OC, Carlin JB: The intra-cluster correlation coefficient in cluster randomized trials: a review of definitions. Int Stat Rev 2009, 77(3):378-394.

11. Passini R Jr, Tedesco RP, Marba ST, Cecatti JG, Guinsburg R, Martinez FE, Nomura ML, Brazilian Network of Studies on Reproductive and Perinatal Health: Brazilian multicenter study on prevalence of preterm birth and associated factors. BMC Pregnancy Childbirth 2010, 10:22.

12. Tedesco RP, Passini R Jr, Cecatti JG, Camargo RS, Pacagnella RC, Sousa MH: Estimation of preterm birth rate, associated factors and maternal morbidity from a Demographic and Health Survey in Brazil. Matern Child Health J 2013, 17(9):1638-1647.

13. SPSS for Windows: Release 20.0. New York: SPSS Inc; 2011.

14. StataCorp: Stata Statistical Software: Release 7, College Station. College Station, TX: StataCorp LP; 2001.

15. Campbell MK, Fayers PM, Grimshaw JM: Determinants of the intracluster correlation coefficient in cluster randomised trials: the case of implementation research. Clin Trials 2005, 2:99-107.

16. Taljaard M, Donner A, Villar J, Wojdyla D, Velazco A, Bataglia V, Bataglia V, Faundes A, Langer A, Narváez A, Valladares E, Carroli G, Zavaleta N, Shah A,
Campodónico L, Romero M, Reynoso S, de Pádua KS, Giordano D, Kublickas M, Acosta A, World Health Organization 2005 Global Survey on Maternal and Perinatal Health Research Group: Intracluster correlation coefficients from the WHO Global Survey on Maternal and Perinatal Health: implications for implementation research. Paediat Perinatal Epidemiol 2005, 2008(22):117-125.

17. Pagel C, Prost A, Lewycka S, Das S, Colbourn T, Mahapatra R, Azad K, Costello A, Osrin D: Intracluster correlation coefficients and coefficients of variation for perinatal outcomes from five cluster-randomised controlled trials in low and middle-income countries: results and methodological implications. Trials 2011, 12:151.

18. Piaggio G, Carroli G, Villar J, Pinol A, Bakketeig L, Lumbiganon P, Bergsjø P, Al-Mazrou Y, Ba'aqeel H, Belizán JM, Farnot U, Berendes H, WHO Antenatal Care Trial Research Group: Methodological considerations on the design and analysis of an equivalence stratified cluster randomization trial. Stat Med 2001, 20:401-416.

19. Campbell SM, Braspenning J, Hutchinson A, Marshall M: Research methods used in developing and applying quality indicators in primary care. Qual Safe Health Care 2002, 11:358-364.

20. Haddad SM, Sousa MH, Cecatti JG, Parpinelli MA, Costa ML, Souza JP, and for the Brazilian Network for Surveillance of Severe Maternal Morbidity Group: Intraclass correlation coefficients in the Brazilian network for surveillance of severe maternal morbidity study. BMC Pregnancy Childbirth 2012, 12:101.

21. Brazilian Ministry of Health: National Registry of Health Facilities. 2013. Available at http://cnes.datasus.gov.br/Lista_Tot_Es_Estado.asp. Accessed on November $27^{\text {th }}, 2013$.

22. Brazilian Ministry of Health: SINASC - National Information System on Live Births. 2011. Available at http://tabnet.datasus.gov.br/cgi/tabcgi.exe?sinasc/ cnv/nvuf.def. Accessed on November $27^{\text {th }}, 2013$.

\section{doi:10.1186/1471-2288-14-54}

Cite this article as: Lajos et al: Intracluster correlation coefficients for the Brazilian Multicenter Study on Preterm Birth (EMIP): methodological and practical implications. BMC Medical Research Methodology 2014 14:54.

\section{Submit your next manuscript to BioMed Central and take full advantage of:}

- Convenient online submission

- Thorough peer review

- No space constraints or color figure charges

- Immediate publication on acceptance

- Inclusion in PubMed, CAS, Scopus and Google Scholar

- Research which is freely available for redistribution

Submit your manuscript at www.biomedcentral.com/submit
C Biomed Central 